\title{
Human Immunodeficiency Virus-Associated Diarrhea: Still an Issue in the Era of Antiretroviral Therapy
}

\author{
Andrew E. Dikman · Emily Schonfeld • \\ Nalinee C. Srisarajivakul $\cdot$ Michael A. Poles
}

Received: 27 August 2014/Accepted: 27 February 2015/Published online: 14 March 2015

(C) The Author(s) 2015. This article is published with open access at Springerlink.com

\begin{abstract}
Over half of patients with human immunodeficiency virus (HIV) experience diarrhea that contributes negatively to quality of life and adherence to antiretroviral therapy (ART). Opportunistic infectious agents that cause diarrhea in patients with HIV span the array of protozoa, fungi, viruses, and bacteria. With global use of ART, the incidence of diarrhea because of opportunistic infections has decreased; however, the incidence of noninfectious diarrhea has increased. The etiology of noninfectious diarrhea in patients with HIV is multifactorial and includes ART-associated diarrhea and gastrointestinal damage related to HIV infection (i.e., HIV enteropathy). A basic algorithm for the diagnosis of diarrhea in patients with HIV includes physical examination, a review of medical history, assessment of HIV viral load and CD4+ T cell count, stool microbiologic assessment, and endoscopic evaluation, if needed. For patients with negative diagnostic results, the diagnosis of noninfectious diarrhea may be considered. Pharmacologic options for the treatment of noninfectious diarrhea are primarily supportive; however, the use of many unapproved agents is based on unstudied and anecdotal information. In addition, these agents can be associated with treatment-limiting adverse events (AEs), such as drug-drug interactions with ART regimens, abuse liability, and additional gastrointestinal AEs. Currently, crofelemer, an antisecretory agent, is the
\end{abstract}

\footnotetext{
A. E. Dikman · E. Schonfeld · M. A. Poles ( $\square)$

Division of Gastroenterology, Department of Medicine, NYU

School of Medicine, Veterans Affairs New York Harbor

Healthcare System, 423 East 23rd Street, Room 11097,

New York, NY 10010, USA

e-mail: michael.poles@nyumc.org
}

N. C. Srisarajivakul · M. A. Poles

NYU Langone Medical Center, New York, NY, USA only therapy approved in the USA for the symptomatic relief of noninfectious diarrhea in patients with HIV on ART.

Keywords Noninfectious · Diarrhea - Antiretroviral therapy · HIV enteropathy · Antisecretory agent · Crofelemer

\section{Introduction}

Advances in the treatment of human immunodeficiency virus (HIV) and acquired immunodeficiency syndrome (AIDS) have transformed this disease into a chronic illness [1]. As a result, individuals with HIV have a longer life expectancy [2]. When HIV is treated early and aggressively, life expectancy approaches that of uninfected individuals [3, 4]. According to the Centers for Disease Control and Prevention (CDC), the annual incidence of HIV has remained stable during the past 10 years [2]. In 2010, the prevalence of HIV in individuals aged over 13 years was estimated to be about $1,148,200$ [5]. Although this number illustrates a dramatic increase in the prevalence of HIV since 1996, it is largely due to the decreased mortality rate associated with the advent of antiretroviral therapy (ART) [2].

Because most cases of diarrhea in the pre-ART era were due to infectious pathogens, it was widely believed that successful treatment would reduce, or even solve, this problem [6, 7]. Although ART has improved the survival and quality of life of patients with HIV, and even decreased the incidence of diarrhea in this population, diarrhea remains a common complaint among these patients and continues to negatively impact the quality of life [6-9]. Furthermore, while the burden of diarrhea in the HIV-infected population remains high, the causes of diarrhea have 
shifted toward noninfectious etiologies [6, 7]. In one survey, $\sim 60 \%$ of patients receiving ART reported having the symptom of diarrhea in the previous month [10]; clinical trial data would suggest that up to $19 \%$ of these events may have been due to the effects of ART itself [11]. In support of this assertion, US historical data of HIV-infected patients with CD4+ T cell counts $<200$ cells $/ \mathrm{mm}^{3}$ were investigated and demonstrated a decline in infectious diarrhea from 53 to $13 \%$ over 3 years (1995-1997); this correlated with the introduction of ART around 1995 [6]. During that same period, the percentage of patients with noninfectious diarrhea increased from 32 to $71 \%$ [6]. A similar trend in etiologic differences has been observed in other countries for patients taking ART versus those not taking ART [12]. This review explores some explanations for the continued burden of diarrhea among patients with HIV, discusses the diagnostic workup, and provides guidance on how HIVassociated noninfectious diarrhea should be treated.

\section{Pathophysiology}

\section{HIV Infection of the Gastrointestinal Tract}

Gut-associated lymphoid tissue (GALT) is the largest collection of lymphoid tissue in the human body [13]. The gastrointestinal (GI) tract is regularly exposed to a complex and diverse assortment of antigens from both microbial and dietary sources [14]. As a result, naïve B and T cells of the gut are constantly interacting with antigens that induce their maturation into plasma cells and memory $\mathrm{T}$ cells, respectively. This persistent stimulation of the immune system leads to a baseline inflammatory state that encourages the production of chemokines and adhesion molecules, which mediate the movement of lymphocytes into the mucosal tissues $[13,15]$. The GI tract is targeted during all phases of HIV infection, but the effects of HIV on the mucosal immune system are most apparent in the acute infection period. Data from simian models with simian immunodeficiency virus [16] and from patients with HIV $[13,17,18]$ show that within weeks of infection, the vast majority of mucosal lamina propria CD4+ lymphocytes are depleted. This depletion occurs well before any decrease in CD4+ T cells is seen in the periphery and likely reflects the greater expression of the $\mathrm{CC}$ chemokine receptor type 5 (CCR5), which functions as the primary coreceptor for the majority of infective HIV strains, on mucosal CD4+ T cells [19]. The expression of the chemokine receptor on these cells supports the entry of the virus, but their state of physiologic activation is responsible for enhanced HIV replication in the mucosal compartment and subsequent mucosal CD4+ T cell depletion. Further, despite the use of potent antiretroviral medications, HIV persists within GALT lymphocytes, even after repletion of
CD4+ T cells in the periphery [20]. Thus, in patients with chronic HIV infection, the mucosal environment contains a paucity of CD4+ T cells but is overpopulated with $\mathrm{CD} 8+\mathrm{T}$ cells and B cells, giving the wrong impression of a healthy mucosal environment at the microscopic level [21].

The etiology of diarrhea in HIV-infected patients can be divided into two major categories: noninfectious and infectious. As treatment of HIV has improved, the increase in peripheral $\mathrm{CD} 4+\mathrm{T}$ cell counts has resulted in a decline in the risk of infection and associated diarrhea (Fig. 1) [22]. Indicative of this shift, noninfectious etiologies of diarrhea have now surpassed infectious causes [6]. Noninfectious diarrhea is defined as pathogen-negative diarrhea and includes ART-associated diarrhea, GI damage related to HIV infection (i.e., HIV enteropathy), and many causes mirroring those seen in gender- and age-matched patients without HIV infection.

Noninfectious Etiologies of Diarrhea

\section{HIV Enteropathy}

HIV enteropathy is an idiopathic form of diarrhea observed in patients with HIV in the absence of an infectious source with characteristic histologic features (Table 1) [8, 23-25]. While the exact mechanisms by which these changes occur in the GI tract are unclear, HIV has been postulated to alter signaling and cellular structure, which may lead to architectural distortion [23]. Several studies have demonstrated crypt epithelial proliferation in response to HIV infection, leading to increased crypt height, subsequent crypt cell encroachment onto villi, and relative decreased villous height resulting in diarrhea and malabsorption [26, 27]. A study by Keating and colleagues that investigated monosaccharide absorption in patients with HIV and AIDS demonstrated that patients with diarrhea had significant malabsorption of all monosaccharides tested [28]. Evidence of malabsorption was reported in patients with both pathogen-negative $(n=7)$ and pathogen-positive $(n=27)$ diarrhea, suggesting that malabsorption may be involved in HIV enteropathy, as well as in pathogen-induced diarrhea.

Other hypotheses for the mechanism of HIV enteropathy include decreased transepithelial electrical resistance, decreased sodium-dependent glucose absorption, and increased intercellular permeability in HIV-infected cells [29]. In vitro studies have demonstrated that gp120, an envelope protein of HIV, induces microtubule disruption, decreases epithelial resistance, and promotes calcium signaling within the cell to affect these cytopathic changes [29, 30]. However, there was no effect of gp120 on chloride secretion.

HIV enteropathy may occur at all stages of HIV infection, from acute HIV to advanced AIDS [23]. Data suggest that HIV may be capable of infecting mucosal epithelial 
Fig. 1 Common causes of diarrhea at different stages of HIV infection and treatment. The shaded boxes indicate causes of diarrhea at different stages of HIV infection based on CD4+ $\mathrm{T}$ cell count. The impact of starting ART on $\mathrm{CD} 4+\mathrm{T}$ cell counts is depicted by the gray dotted line. ART antiretroviral therapy, $C M V$ cytomegalovirus, $G I$ gastrointestinal, $H I V$ human immunodeficiency virus, $M A C$ Mycobacterium avium complex. Reprinted with permission from [22]

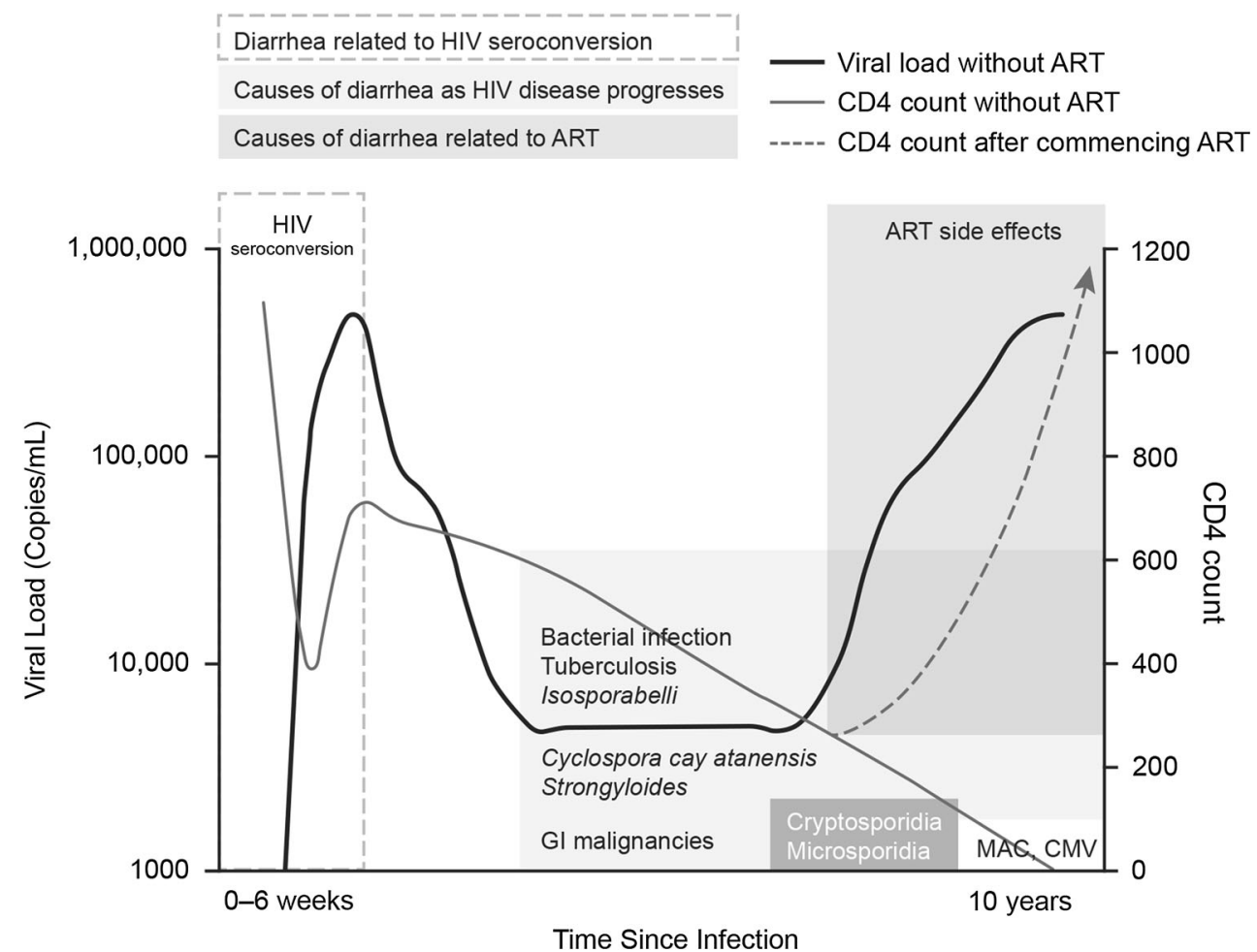

Table 1 Idiopathic diarrhea in patients with HIV

\begin{tabular}{ll}
\hline Condition & Clinical presentation/definition \\
\hline HIV enteropathy [23] & May be associated with \\
& GI inflammation \\
& Malabsorption of vitamin B $_{12}$ and bile acid \\
& Increased intestinal permeability \\
& Weight loss \\
& Histologically associated with \\
& Inflammatory lymphocyte infiltrates \\
& Damage to the GI epithelium, including \\
& Villous atrophy, crypt hyperplasia, and villous blunting \\
& Defined by the ACG as abdominal pain or associated with altered bowel habits over a period of $\geq 3$ months \\
& Defined by Rome III criteria as recurrent abdominal pain or discomfort for $\geq 3$ days/month in the last 3 months \\
& with symptom onset at $\geq 6$ months before diagnosis and associated with $\geq 2$ of the following: \\
Irritable bowel syndrome & Improvement with defecation \\
[24, 25] & Onset associated with change in stool frequency \\
& Onset associated with change in stool form \\
& Defined by Rome III criteria as $\geq 75 \%$ of stools that are loose (mushy) and without pain for $\geq 3$ months with \\
& symptom onset $\geq 6$ months before diagnosis
\end{tabular}

Reprinted with permission from [8]

ACG American College of Gastroenterology, GI gastrointestinal, HIV human immunodeficiency virus

cells, resulting in direct effects on epithelial cell function [31]. Further, microscopic inflammation may be mechanistically involved in HIV enteropathy [23]. While HIV rapidly and severely depletes mucosal $\mathrm{T}$ cells, the total mucosal $\mathrm{T}$ cell population remains largely unchanged [21]. This reflects greater mucosal infiltration by activated $\mathrm{CD} 8+\mathrm{T}$ cells. These cells are primed to produce proinflammatory cytokines and chemokines, which may directly 
damage the mucosal barrier, resulting in decreased transepithelial resistance and diarrhea [21, 23]. This has been shown to lead to malabsorption of vitamin $B_{12}$, bile acid, and monosaccharides; thus, HIV enteropathy can also be more specifically defined by its physiologic effect on small bowel function $[23,28]$.

\section{ART-Associated Diarrhea}

While diarrhea is an adverse effect of ART, protease inhibitors seem to be most strongly associated with diarrhea (Table 2) [32]. In mouse models, protease inhibitors and reverse transcriptase inhibitors were found to significantly increase water and electrolyte secretion into the intestinal lumen in vivo [33]. Rufo and colleagues demonstrated that protease inhibitors in general and nelfinavir in particular potentiate signaling through muscarinic- and calcium-dependent receptors of intestinal cells, resulting in increased chloride secretion into the lumen [34]. This study also showed that sodium and chloride concentrations in stool samples from patients with HIV taking nelfinavir were elevated, consistent with secretory diarrhea. In an in vitro study, Bode and colleagues found that protease inhibitors induced apoptosis of human intestinal epithelium, compromising barrier function in the cells and thereby increasing water secretion in the gut lumen [35]. Wu and colleagues also investigated the mechanism by which protease inhibitors cause diarrhea and found that lopinavir and ritonavir (notably not amprenavir) induced endoplasmic reticulum dysfunction in the intestinal epithelial cells [36].

Table 2 Incidence of ART-associated diarrhea [32]

\begin{tabular}{ll}
\hline ART class & $\begin{array}{l}\text { Reported incidence } \\
\text { of diarrhea }(\%)\end{array}$ \\
\hline Protease inhibitors & $7-28$ \\
Lopinavir/ritonavir & $2-3$ \\
Atazanavir/ritonavir & $9-14$ \\
Darunavir/ritonavir & \\
Nonnucleoside reverse transcriptase inhibitors & $3-14$ \\
Efavirenz & $<1-2$ \\
Nevirapine & $<2$ \\
Rilpivirine & \\
Nucleoside reverse transcriptase inhibitors & $9-16$ \\
Tenofovir disoproxil fumarate & 7 \\
Abacavir & \\
Integrase inhibitors & $<1$ \\
Raltegravir & $\sim 1$ \\
Dolutegravir & 12 \\
Elvitegravir &
\end{tabular}

Adapted with permission from [32]

$A R T$ antiretroviral therapy

${ }^{\text {a }}$ Coformulated elvitegravir/cobicistat/emtricitabine/tenofovir
When exposed to protease inhibitors, the cells were found to have decreased alkaline phosphatase activity and thereby an increase in unfolded proteins. The accumulation of defective proteins in the cytosol may persistently activate the cell's unfolded protein response, a specific signaling pathway that aims to return the cell's protein folding function back to normal. If the levels of unfolded proteins do not decrease, the cell may induce apoptosis.

\section{Other Causes of Noninfectious Diarrhea}

Functional bowel disorders, such as irritable bowel syndrome (IBS), are additional conditions that may present with diarrhea [8]. In a survey conducted in a Veterans Affairs outpatient setting, IBS was more common in HIVpositive patients compared with HIV-negative patients [37]. Another cause of noninfectious diarrhea is small intestinal bacterial overgrowth (SIBO) [38], a condition in which increased bacteria in the small intestine leads to multiple GI symptoms, including abdominal bloating and discomfort, diarrhea, and malabsorption [39]. This condition may be more common in those with anatomic abnormalities and motility disorders, but does not appear to be a common cause of diarrhea in those with HIV [40].

\section{Infectious Etiologies of Diarrhea}

Given the multitude of differences in standard of living among developed versus developing countries and differences in availability of care for patients with HIV, the incidence and type of various diarrhea-associated infections in immunocompromised patients may vary substantially by region [41, 42]. In addition, diarrhea experienced by HIV-infected individuals can be caused by pathogens that are unique to the HIV population or by pathogens that cause diarrhea in the immunocompetent host [41, 43]. For example, Salmonella, Shigella, Campylobacter, Escherichia coli, and enterotropic viruses cause diarrhea in both the immunocompetent and HIV-infected patients. In addition to these pathogens, patients with HIV who are profoundly immunosuppressed, with a CD4+ $\mathrm{T}$ cell count $<200$ cells $/ \mathrm{mm}^{3}$, are also susceptible to opportunistic infections [44]. These opportunistic infections can be organized into four general categories of organisms: protozoa, fungi, viruses, and bacteria (Table 3) [41, 45-48].

\section{Protozoa}

Cryptosporidiosis is caused by an intracellular pathogen, Cryptosporidium [49]. Infection with Cryptosporidium parvum is a common cause of diarrhea worldwide [45]. There is an estimated rate of $\sim 60,000$ cases of 
Table 3 Infectious causes of diarrhea in patients with HIV diagnosed by endoscopy or colonoscopy [41, 45-48]

\begin{tabular}{lll}
\hline Pathogen & Endoscopy & Colonoscopy \\
\hline Bacteria & Salmonella & Salmonella, Shigella, Campylobacter \\
& Enteropathogenic and enterotoxigenic & Enterohemorrhagic E coli, enteroinvasive E coli \\
& Small intestine bacterial overgrowth & \\
& Mycobacterium avium complex & Clostridium difficile \\
& Cryptosporidia (small intestine) & Mycobacterium avium complex \\
Protozoa & Microsporidia (most often in proximal jejunum) & Cryptosporidia \\
& Giardia (upper small intestine) & Entamoeba histolytica \\
& Cyclospora (small intestine) & \\
Isospora (small intestine) & \\
CMV & HSV & CMV \\
& Histoplasma (most commonly terminal ileum; & HSV (rectum, sigmoid) \\
Fungi & can affect any part of the GI tract) & Adenovirus \\
\end{tabular}

Based on either appearance of mucosa in endoscopy/colonoscopy or mucosal biopsy

$C M V$ cytomegalovirus, $G I$ gastrointestinal, $H I V$ human immunodeficiency virus, $H S V$ herpes simplex virus

cryptosporidial infection per year in the USA [50]; risk of Cryptosporidium parvum infection is greater in developing countries where there is poor sanitation [51-53]. It spreads from person to person or via contaminated water (e.g., drinking water or recreational water sites) [54]. Although the protozoa cause a mild, self-limited disease in immunocompetent individuals, it can manifest as severe, watery diarrhea in HIV-infected patients and it can also occasionally lead to a chronic infection [49]. In the profoundly immunocompromised, Cryptosporidium parvum can lead to a malabsorptive syndrome, severe dehydration, and electrolyte derangements [49, 55].

Other protozoal infections that commonly affect patients with HIV include Microsporidia, Isospora, Cyclospora, and, less commonly, Toxoplasma and Leishmania species, which like Cryptosporidium, affect the small intestine and can lead to malabsorptive diarrheal illnesses [41]. Similarly, Giardia also is a very common protozoal pathogen in both HIV-infected and immunocompetent hosts and infects the small intestinal mucosa. Entamoeba histolytica is a protozoal pathogen that can cause colitis in the severely immunocompromised HIV-infected patient and in rare and severe circumstances can lead to ulceration, hematochezia, and even toxic megacolon.

\section{Viruses}

Cytomegalovirus (CMV) is the most common viral GI pathogen in patients with AIDS [44]. CMV can affect the entire GI tract but classically leads to diarrhea by causing colitis characterized by rectal bleeding, abdominal pain, and systemic signs such as fevers and weight loss [55]. HIV infection itself can cause a diarrheal illness as described below, and multiple other viruses have been implicated as diarrheal pathogens, including adenovirus, coronavirus, herpes simplex virus, rotavirus, and norovirus $[44,46]$.

\section{Fungi}

Rarely have fungi been reported to cause diarrhea in HIVinfected patients [44]. Of the infections associated with endemic fungi, histoplasmosis is the most common fungal infection requiring hospitalization and can affect any part of the GI tract, causing diarrhea, weight loss, and fever [56].

\section{Bacteria}

Mycobacterium avium complex (MAC) typically causes diarrhea in patients with AIDS with profoundly suppressed immune systems (i.e., CD4+ T cell count $<50$ cells $/ \mathrm{mm}^{3}$ ) [44]. Symptoms are varied, but they usually reflect the systemic nature of the disseminated infection and include fever and weight loss [45]. MAC usually involves the small intestine; however, it can affect the entire GI tract $[55,57]$.

Salmonella, Shigella, Campylobacter, and E coli are bacterial infections of the GI tract that can present with diarrhea [41]. They are usually spread through food and water contamination. Patients with an impaired immune system can become asymptomatic carriers of some pathogens (e.g., Shigella, Campylobacter). Clostridium difficile should be investigated in patients who have recently taken antibiotics [47]. It causes pseudomembranous colitis that 
can progress to toxic megacolon in severe infections. Clostridium difficile is more common in patients with advanced AIDS $\left(\mathrm{CD} 4+\mathrm{T}\right.$ cell count $<50$ cells $\left./ \mathrm{mm}^{3}\right)$. In one study evaluating the incidence of bacterial diarrhea in patients with HIV, Clostridium difficile was the most common identified culprit, accounting for $53.6 \%$ of 1115 episodes of diarrhea that had a bacterial pathogen isolated [36].

Overall, protozoa, fungi, MAC, and CMV GI infections are usually seen only in patients with HIV and other immunocompromised patients [58]. As noted earlier, with improved therapy, patients infected with HIV are less prone to develop diarrhea due to infectious pathogens and are more prone to noninfectious causes [48].

\section{Diagnosis}

The basic algorithm for the diagnosis and evaluation of diarrhea in patients with HIV is similar to the examination of diarrhea in the immunocompetent host and starts with a thorough medical history [55]. This includes the duration of the diarrhea, constitutional and systemic symptoms, the presence or severity of abdominal pain, and questions on the characteristics of diarrhea (e.g., large versus small volume; infrequent or nocturnal versus frequent) to help localize the source to the large or small intestine and narrow the differential diagnosis (Fig. 2) [8, 55]. Classically, diarrhea from pathology in the small intestine presents as voluminous and watery, occasionally associated with weight loss as well as signs and symptoms of malabsorption [59]. Bloating, nausea, and cramping may also indicate a small intestine source. Diarrhea from the large intestine is typically characterized by smaller, more frequent bowel movements [48]. If there is inflammation of the rectum and anus, patients may describe tenesmus and painful defecation, which may be associated with hematochezia. A careful review of medications, travel history, contact with ill individuals, recent ingestions, family history, surgical history, and social history is important in evaluating acute and chronic diarrhea in the patient infected with HIV [8].

Physical examination and medical history of a patient with HIV and diarrhea may help to evaluate the chronicity of the diarrhea and the severity of illness and thereby focus the differential diagnosis. Nutritional status should be assessed by evaluating for bitemporal wasting, weight changes, skin turgor, and mucosal dehydration. Basic vital signs and orthostatic vital signs are essential to gauge the severity of the patient's illness and the degree of the patient's volume depletion. Documented fever may be an important clue of an infectious etiology, though the absence of fever in an immunocompromised host does not rule out the possibility of an infection. The GI examination may reveal tenderness to palpation, possibly indicative of pancreatic pathology or colitis. Hepatosplenomegaly may represent mycobacterial infection, hepatitis, or fungal or malignant causes of diarrhea. A rectal examination is of integral importance because it may reveal signs of sexually transmitted infections, bleeding, tenderness, and masses, all of which may help to establish a diagnosis. A careful, comprehensive examination of the patient is essential to evaluate the severity of disease, narrow the diagnosis, and guide the management.

Further diagnostic evaluation may also aid in a diagnosis [8]. Laboratory tests should include comprehensive metabolic panel, complete blood count with cell differential, blood cultures, HIV viral load, and CD4+ T cell count to gauge the level of immune suppression. Stool examinations should include fecal lactoferrin, fecal leukocytes, fecal calprotectin, fecal occult blood, and Clostridium difficile stool culture, as well as three separate samples of ova and parasites. Infection with Cryptosporidium parvum is most commonly diagnosed by microscopic identification or enzyme immunoassay of the organisms in the stool of patients but can also be made by biopsy of the GI tract or aspiration from the biliary tree during endoscopy. Diagnosis of Giardia can be made by immunoassay of the stool but, again, can be identified on endoscopic biopsy or on luminal aspiration during endoscopy. Diagnosis of bacterial infections of the GI tract, such as Salmonella, is made by stool culture.

If no pathogen is identified, further workup is needed with an endoscopic examination [8]. Colonoscopy with biopsy is necessary for diagnosis of CMV and HSV and may reveal hemorrhage, colitis, and ulcers [46]. There is some debate as to whether sigmoidoscopy or full colonoscopy would be beneficial; one colonoscopy study ( $n=44)$ showed that nearly $40 \%$ of 18 patients with CMV-associated colitis had disease localized to the cecum [60]. However, a prospective study comparing sigmoidoscopy and full colonoscopy showed that the sensitivity of a sigmoidoscopy was $77 \%$ for enteric pathogens and full colonoscopy only yielded a small increase in sensitivity to $82 \%$, with no additional cases of CMV-associated colitis identified [61]. Diagnosis of MAC infection within the GI tract requires endoscopy, which may identify ulcerations, erythema, or normal mucosa but may also reveal foamy macrophages and positive culture via biopsy [45]. Diagnosis of fungal infections may be made histologically from biopsies taken for endoscopy or colonoscopy [58]. Mucosal biopsy can also help diagnose inflammatory bowel disease. For patients with negative diagnostic results, the diagnosis of noninfectious diarrhea can be made.

\section{Treatment}

The treatment of infectious diarrhea is outside the scope of this article, and this section will focus on the treatment of noninfectious diarrhea. If no other cause of diarrhea is 
Fig. 2 General algorithm for the diagnosis and management of diarrhea in patients with HIV. $A R T$ antiretroviral therapy, $H I V$ human immunodeficiency virus. Reprinted with permission from [8]

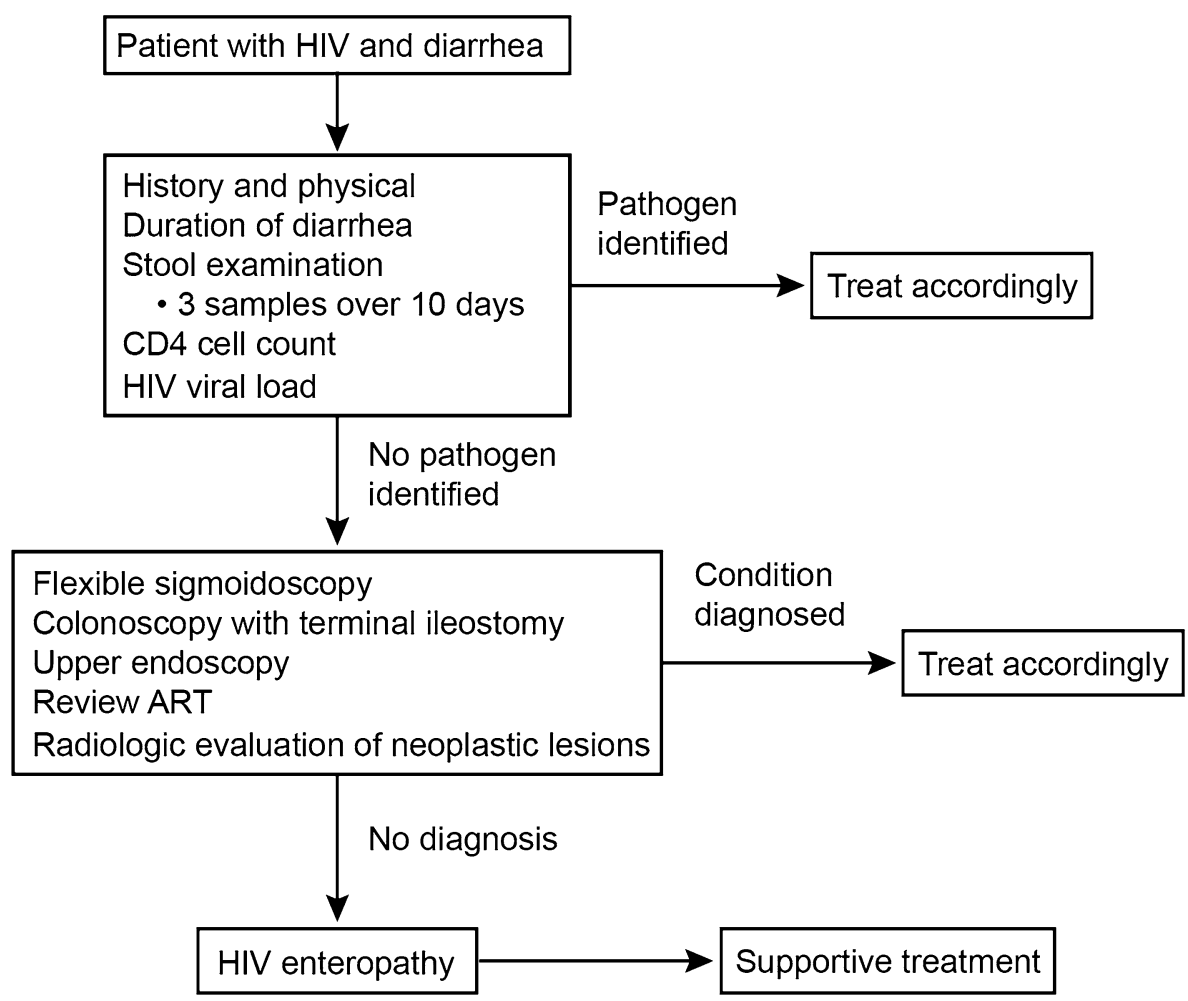

identified, patient medications should be reviewed to evaluate for an iatrogenic cause of the diarrhea. Pharmacologic options for the treatment of noninfectious diarrhea in patients with HIV are primarily supportive. Hydration via intravenous and oral routes, repletion of electrolytes, and treating the underlying cause, if possible, are important therapies for any patient with diarrhea [62]. Noninfectious diarrhea can be managed by modifying ART and controlling symptoms with medications and lifestyle modification. However, clinical guidelines for patients with HIV recommend careful evaluation of the symptoms and symptomatic management of ART-related AEs (e.g., diarrhea) before switching ART, with supportive care (e.g., antidiarrheals) generally allowing for continuation of prescribed ART therapy [63, 64]. However, cessation of ART ("drug holiday") is generally not advised as a management strategy.

Antidiarrheal medications used in noninfectious diarrhea can be divided into several classes: adsorbents, antimotility agents, and antisecretory agents (Table 4) [8, 32, 62, 65-71]. Adsorbent drugs bind bacterial toxins, fluids, and other compounds in the intestines to improve stool consistency [65]. Drugs in this category include bismuth subsalicylate, kaolin/pectin, and attapulgite (aluminum magnesium silicate purified from clay). Data on the use of adsorbents in patients with HIV are limited to one study in which the efficacy of attapulgite was not better than placebo in the management of diarrhea $[65,72]$.
Antimotility agents include loperamide, diphenoxylate/ atropine, and tincture of opium [65]. These agents act upon opioid receptors in the gut to slow motility by decreasing peristalsis and increasing tone in the large intestine. This allows for greater fecal transit time and therefore longer time for water absorption.

The antimotility agent diphenoxylate crosses the bloodbrain barrier and can cause central effects analogous to other opioid agonists [62]. To prevent the abuse of diphenoxylate, it is usually sold as a combination agent with atropine. Loperamide does not cross the blood-brain barrier and does not have these adverse effects. One disadvantage to loperamide is that it may interact with ART agents, such as ritonavir and saquinavir, which can limit its use for long-term therapy [62, 67]. However, loperamide has been shown in a small trial to decrease the number of bowel movements in patients with protease inhibitor-induced diarrhea [73]. The use of the combination of lowdose diphenoxylate/atropine may be efficacious for treating protease inhibitor-induced diarrhea; however, it appears that this combination had no beneficial effect in patients who were refractory to loperamide therapy [66]. Although not studied for the treatment of diarrhea in patients with HIV, tincture of opium is considered more effective than loperamide as an antimotility agent, and it can be titrated easily. Tincture of opium may be considered early in the treatment algorithm for patients with severe HIV-associated diarrhea. 
Table 4 Pharmacologic treatment of noninfectious diarrhea in patients with HIV [8, 32, 62, 65-71]

\begin{tabular}{|c|c|c|}
\hline Class & Mechanism of action & Examples \\
\hline Adsorbents & $\begin{array}{l}\text { Adsorb fluids to improve stool } \\
\text { consistency }\end{array}$ & $\begin{array}{l}\text { Attapulgite } \\
\text { Bismuth } \\
\text { subsalicylate } \\
\text { Kaolin }^{\mathrm{a}} \\
\text { Pectin }\end{array}$ \\
\hline $\begin{array}{l}\text { Antimotility } \\
\text { agents }\end{array}$ & $\begin{array}{l}\text { Increases fecal transit time by } \\
\text { decreasing bowel activity, } \\
\text { thereby reducing fluid and } \\
\text { electrolyte loss }\end{array}$ & $\begin{array}{l}\text { Diphenoxylate- } \\
\text { atropine } \\
\text { Loperamide } \\
\text { Octreotide }\end{array}$ \\
\hline $\begin{array}{l}\text { Antisecretory } \\
\text { agents }\end{array}$ & $\begin{array}{l}\text { Inhibits secretion of water and } \\
\text { electrolytes into the GI tract }\end{array}$ & $\begin{array}{l}\text { Crofelemer } \\
\text { Octreotide } \\
\text { Racecadotril }\end{array}$ \\
\hline
\end{tabular}

GI gastrointestinal, HIV human immunodeficiency virus

a Type of clay

Antisecretory agents, such as octreotide, racecadotril, and crofelemer, directly inhibit secretory processes within enterocytes [62, 68-71]. The mechanism of action of octreotide, administered subcutaneously, is unclear, but it is believed to alter the binding of vasoactive intestinal peptide, therefore acting as an antimotility and antisecretory agent $[8,62,74]$. Published data conflict about the efficacy of octreotide in treating diarrhea in patients with AIDS [75, 76]. Oral racecadotril is an enkephalinase inhibitor, which decreases the breakdown of endogenous gut opioids, thereby decreasing the secretion of water and electrolytes into the gut lumen [69]. Racecadotril is not currently available in the USA.

Orally administered crofelemer is a dual inhibitor of cAMP-stimulated cystic fibrosis transmembrane conductance regulator (CFTR) and calcium-stimulated calciumactivated chloride channels (CaCC) in the gut [77]. Crofelemer is a minimally absorbed GI drug derived from the latex of the Croton lechleri tree, and has reportedly been used by Amazonian tribes for diarrheal relief [68]. Crofelemer is the only agent approved in the USA for the symptomatic relief of noninfectious diarrhea in patients with HIV on ART [78]. Compared with placebo, crofelemer has been shown, in a randomized, double-blind, placebo-controlled trial with an open-label extension, to significantly reduce symptoms of noninfectious diarrhea in patients with HIV receiving ART (percentage of patients with $\leq 2$ watery stools per week for at least 2 of 4 weeks during placebo-controlled phase: 17.6 versus $8.0 \%$, respectively; $P=0.01$ ) [70]. In addition, crofelemer has no known drug interactions with ART drugs, is minimally absorbed, and does not have a negative impact on the clinical immune parameters (e.g., HIV viral load and CD4+ T cell counts) $[68,70,71]$.

\section{Conclusions}

Diarrhea is a common complication of HIV infection that has substantial clinical ramifications. The differential diagnosis for diarrhea in patients with HIV is broad. While infection has historically been the major cause of diarrhea in patients with HIV, with the widespread use of ART therapy, noninfectious diarrhea has become a burden in this population. Medications used for noninfectious diarrhea include antimotility and antisecretory agents, including crofelemer, which has been shown to significantly reduce symptoms of noninfectious diarrhea. Improved treatment of noninfectious diarrhea will likely improve HIV medication adherence and quality of life.

Acknowledgments Technical editorial assistance was provided, under the direction of the authors, by Pratibha Hebbar, PhD, Synchrony Medical Communications, LLC, West Chester, PA. Funding for this support was provided by Salix Pharmaceuticals, Inc.

\section{Conflict of interest None.}

Open Access This article is distributed under the terms of the Creative Commons Attribution Noncommercial License which permits any noncommercial use, distribution, and reproduction in any medium, provided the original author(s) and the source are credited.

\section{References}

1. Moss JA. HIV/AIDS review. Radiol Technol. 2013;84:247-267.

2. Centers for Disease Control and Prevention. HIV surveillanceUnited States, 1981-2008. MMWR Morb Mortal Wkly Rep. 2011;60:689-693.

3. The Collaboration of Observational HIV Epidemiological Research Europe (COHERE) in Euro Coord, Lewden C, De Wit S, et al. All-cause mortality in treated HIV-infected adults with CD4 $>/=500 / \mathrm{mm}^{3}$ compared with the general population: evidence from a large European observational cohort collaboration. Int $J$ Epidemiol. 2012;41:433-445.

4. van Sighem AI, Gras LA, Reiss P, Brinkman K, de Wolf F. Life expectancy of recently diagnosed asymptomatic HIV-infected patients approaches that of uninfected individuals. In: Presented at: 17th Conference on Retroviruses and Opportunistic Infections; February 16-19, 2010; San Francisco, CA. Poster 526.

5. Centers for Diease Control and Prevention National Center for HIV/ AIDS Viral Hepatitis STD and TB Prevention. HIV in the United States: At a GLANCE. Atlanta, GA: Center for Disease Control and Prevention; 2013. http://www.cdc.gov/hiv/resources/factsheets/PDF/ stats_basics_factsheet.pdf. Report no. CS2388337B.

6. Call SA, Heudebert G, Saag M, Wilcox CM. The changing etiology of chronic diarrhea in HIV-infected patients with CD4 cell counts less than 200 cells $/ \mathrm{mm}^{3}$. Am J Gastroenterol. 2000;95:3142-3146.

7. Siddiqui U, Bini EJ, Chandarana K, et al. Prevalence and impact of diarrhea on health-related quality of life in HIV-infected patients in the era of highly active antiretroviral therapy. J Clin Gastroenterol. 2007;41:484-490.

8. MacArthur RD, DuPont HL. Etiology and pharmacologic management of noninfectious diarrhea in HIV-infected individuals in the highly active antiretroviral therapy era. Clin Infect Dis. 2012;55:860-867. 
9. Gupta R, Ordonez RM, Koenig S. Global impact of antiretroviral therapy-associated diarrhea. AIDS Patient Care STDS. 2012;26: 711-713.

10. daCosta DiBonaventura M, Gupta S, Cho M, Mrus J. The association of HIV/AIDS treatment side effects with health status, work productivity, and resource use. AIDS Care. 2012;24:744-755.

11. Hill A, Balkin A. Risk factors for gastrointestinal adverse events in HIV treated and untreated patients. AIDS Rev. 2009;11:30-38.

12. Bachur TP, Vale JM, Coelho IC, Queiroz TR, Chaves CS. Enteric parasitic infections in HIV/AIDS patients before and after the highly active antiretroviral therapy. Braz J Infect Dis. 2008;12:115-122.

13. Mehandru S. The gastrointestinal tract in HIV-1 infection: questions, answers, and more questions! PRN Noteb. 2007;12:1-10.

14. Veazey R, Lackner A. The mucosal immune system and HIV-1 infection. AIDS Rev. 2003;5:245-252.

15. Kunkel EJ, Boisvert J, Murphy K, et al. Expression of the chemokine receptors CCR4, CCR5, and CXCR3 by human tissueinfiltrating lymphocytes. Am J Pathol. 2002;160:347-355.

16. Veazey RS, DeMaria M, Chalifoux LV, et al. Gastrointestinal tract as a major site of $\mathrm{CD} 4+\mathrm{T}$ cell depletion and viral replication in SIV infection. Science. 1998;280:427-431.

17. Mehandru S, Poles MA, Tenner-Racz K, et al. Primary HIV-1 infection is associated with preferential depletion of CD4+ T lymphocytes from effector sites in the gastrointestinal tract. $J$ Exp Med. 2004;200:761-770.

18. Mehandru S, Poles MA, Tenner-Racz K, et al. Mechanisms of gastrointestinal CD4+ T-cell depletion during acute and early human immunodeficiency virus type 1 infection. $J$ Virol. 2007;81:599-612.

19. Anton PA, Elliott J, Poles MA, et al. Enhanced levels of functional HIV-1 co-receptors on human mucosal $\mathrm{T}$ cells demonstrated using intestinal biopsy tissue. AIDS. 2000;14:1761-1765.

20. Chun TW, Nickle DC, Justement JS, et al. Persistence of HIV in gut-associated lymphoid tissue despite long-term antiretroviral therapy. J Infect Dis. 2008;197:714-720.

21. Kotler DP. HIV infection and the gastrointestinal tract. AIDS. 2005;19:107-117.

22. Feasey NA, Healey P, Gordon MA. Review article: the aetiology, investigation and management of diarrhoea in the HIV-positive patient. Aliment Pharmacol Ther. 2011;34:587-603.

23. Brenchley JM, Douek DC. The mucosal barrier and immune activation in HIV pathogenesis. Curr Opin HIV AIDS. 2008;3:356-361.

24. Longstreth GF, Thompson WG, Chey WD, Houghton LA, Mearin F, Spiller RC. Functional bowel disorders. Gastroenterology. 2006;130:1480-1491.

25. Brandt LJ, Chey WD, Foxx-Orenstein AE, et al. An evidencebased position statement on the management of irritable bowel syndrome. Am J Gastroenterol. 2009;104:S1-35.

26. Batman PA, Miller AR, Forster SM, Harris JR, Pinching AJ, Griffin GE. Jejunal enteropathy associated with human immunodeficiency virus infection: quantitative histology. J Clin Pathol. 1989;42:275-281.

27. Batman PA, Kotler DP, Kapembwa MS, et al. HIV enteropathy: crypt stem and transit cell hyperproliferation induces villous atrophy in HIV/Microsporidia-infected jejunal mucosa. AIDS. 2007;21:433-439.

28. Keating J, Bjarnason I, Somasundaram S, et al. Intestinal absorptive capacity, intestinal permeability and jejunal histology in HIV and their relation to diarrhoea. Gut. 1995;37: 623-629.

29. Maresca M, Mahfoud R, Garmy N, Kotler DP, Fantini J, Clayton F. The virotoxin model of HIV-1 enteropathy: involvement of GPR15/Bob and galactosylceramide in the cytopathic effects induced by HIV-1 gp120 in the HT-29-D4 intestinal cell line. $J$ Biomed Sci. 2003;10:156-166.
30. Clayton F, Kotler DP, Kuwada SK, et al. Gp120-induced Bob/ GPR15 activation: a possible cause of human immunodeficiency virus enteropathy. Am J Pathol. 2001;159:1933-1939.

31. Liu R, Huang L, Li J, et al. HIV Infection in gastric epithelial cells. J Infect Dis. 2013;208:1221-1230.

32. MacArthur RD. Clinical Focus: Evolving Options for Managing Noninfectious Diarrhea in HIV-Infected Patients. Clinical Care Options ${ }^{\circledR}$ HIV; 2013. http://www.clinicaloptions.com/HIV/Treatment\%20Updates/Noninfectious\%20Diarhea/CCO\%20Slideset/Slideset.aspx.

33. Braga Neto MB, Aguiar CV, Maciel JG, et al. Evaluation of HIV protease and nucleoside reverse transcriptase inhibitors on proliferation, necrosis, apoptosis in intestinal epithelial cells and electrolyte and water transport and epithelial barrier function in mice. BMC Gastroenterol. 2010;10:90.

34. Rufo PA, Lin PW, Andrade A, et al. Diarrhea-associated HIV-1 APIs potentiate muscarinic activation of $\mathrm{Cl}$-secretion by $\mathrm{T} 84$ cells via prolongation of cytosolic $\mathrm{Ca} 2+$ signaling. Am J Physiol Cell Physiol. 2004;286:C998-C1008.

35. Bode H, Lenzner L, Kraemer OH, et al. The HIV protease inhibitors saquinavir, ritonavir, and nelfinavir induce apoptosis and decrease barrier function in human intestinal epithelial cells. Antivir Ther. 2005;10:645-655.

36. Wu X, Sun L, Zha W, et al. HIV protease inhibitors induce endoplasmic reticulum stress and disrupt barrier integrity in intestinal epithelial cells. Gastroenterology. 2010;138:197-209.

37. Herzog K, Williams R, Cho I, Tenner C, Poles M. Irritable bowel syndrome and HIV: a cross sectional study of the severity of gastrointestinal symptoms and HIV-infected subjects. Am J Gastroenterol. 2010;105:S479.

38. Pignata C, Budillon G, Monaco G, et al. Jejunal bacterial overgrowth and intestinal permeability in children with immunodeficiency syndromes. Gut. 1990;31:879-882.

39. Sachdev AH, Pimentel M. Gastrointestinal bacterial overgrowth: pathogenesis and clinical significance. Ther Adv Chronic Dis. 2013;4:223-231.

40. Wilcox CM, Waites KB, Smith PD. No relationship between gastric $\mathrm{pH}$, small bowel bacterial colonisation, and diarrhoea in HIV-1 infected patients. Gut. 1999;44:101-105.

41. Rossit AR, Gonçalves AC, Franco C, Machado RL. Etiological agents of diarrhea in patients infected by the human immunodeficiency virus1: a review. Rev Inst Med Trop Sao Paulo. 2009;51:59-65.

42. Krones E, Hogenauer C. Diarrhea in the immunocompromised patient. Gastroenterol Clin North Am. 2012;41:677-701.

43. Sanchez TH, Brooks JT, Sullivan PS, et al. Bacterial diarrhea in persons with HIV infection, United States, 1992-2002. Clin Infect Dis. 2005;41:1621-1627.

44. Cello JP, Day LW. Idiopathic AIDS enteropathy and treatment of gastrointestinal opportunistic pathogens. Gastroenterology. 2009; 136:1952-1965.

45. Zacharof A. AIDS-Related diarrhea-pathogenesis, evaluation and treatment. Ann Gastroenterol. 2001;14:22-26.

46. García-Pagán JC, Caca K, Bureau C, et al. Early use of TIPS in patients with cirrhosis and variceal bleeding. $N$ Engl J Med. 2010;362:2370-2379.

47. Haines CF, Moore RD, Bartlett JG, et al. Clostridium difficile in a HIV-infected cohort: incidence, risk factors, and clinical outcomes. AIDS. 2013;27:2799-2807.

48. Mönkemüller KE, Wilcox CM. Investigation of diarrhea in AIDS. Can J Gastroenterol. 2000;14:933-940.

49. Bouzid M, Hunter PR, Chalmers RM, Tyler KM. Cryptosporidium pathogenicity and virulence. Clin Microbiol Rev. 2013;26:115-134.

50. Scallan E, Hoekstra RM, Angulo FJ, et al. Foodborne illness acquired in the United States-major pathogens. Emerg Infect Dis. 2011;17:7-15. 
51. Girma M, Teshome W, Petros B, Endeshaw T. Cryptosporidiosis and Isosporiasis among HIV-positive individuals in south Ethiopia: a cross sectional study. BMC Infect Dis. 2014;14:100.

52. Mahmud MA, Bezabih AM, Gebru RB. Risk factors for intestinal parasitosis among antiretroviral-treated HIV/AIDS patients in Ethiopia. Int J STD AIDS. 2014;25:778-784.

53. Baldursson S, Karanis P. Waterborne transmission of protozoan parasites: review of worldwide outbreaks - an update 2004-2010. Water Res. 2011;45:6603-6614.

54. Yoder JS, Beach MJ. Cryptosporidium surveillance and risk factors in the United States. Exp Parasitol. 2010;124:31-39.

55. Lew EA, Poles MA, Dieterich DT. Diarrheal diseases associated with HIV infection. Gastroenterol Clin N Am. 1997;26:259-290.

56. Goodwin RA Jr, Shapiro JL, Thurman GH, Thurman SS, Des Prez RM. Disseminated histoplasmosis: clinical and pathologic correlations. Medicine (Baltimore). 1980;59:1-33.

57. Sun HY, Chen MY, Wu MS, et al. Endoscopic appearance of GI mycobacteriosis caused by the Mycobacterium avium complex in a patient with AIDS: case report and review. Gastrointest Endosc. 2005;61:775-779.

58. Poles MA, Bini EJ, Cohen J. Gastrointestinal infections in patients infected with HIV-1. Curr Treat Options Infect Dis. 2003;5:219-235.

59. Murray JA, Rubio-Tapia A. Diarrhoea due to small bowel diseases. Best Pract Res Clin Gastroenterol. 2012;26:581-600.

60. Dieterich DT, Rahmin M. Cytomegalovirus colitis in AIDS: presentation in 44 patients and a review of the literature. $J$ Acquir Immune Defic Syndr. 1991;4:S29-S35.

61. Kearney DJ, Steuerwald M, Koch J, Cello JP. A prospective study of endoscopy in HIV-associated diarrhea. Am J Gastroenterol. 1999;94:596-602.

62. Morpeth SC, Thielman NM. Diarrhea in patients with AIDS. Curr Treat Options Gastroenterol. 2006;9:23-37.

63. Health Resources and Services Administration HIV/AIDS Bureau. Guide for HIV/AIDS Clinical Care. Rockville, MD: U.S. Department of Health and Human Services; Health Resources and Services Administration; HIV/AIDS Bureau; 2011.

64. Panel on Antiretroviral Guidelines for Adults and Adolescents. Guidelines for the Use of Antiretroviral Agents in HIV-1-Infected Adults and Adolescents. Washington, DC: Department of Health and Human Services; 2014. http://aidsinfo.nih.gov/contentfiles/ lvguidelines/adultandadolescentgl.pdf.

65. Nwachukwu CE, Okebe JU. Antimotility agents for chronic diarrhoea in people with HIV/AIDS. Cochrane Database Syst Rev. 2008;8:CD005644.
66. Sherman DS, Fish DN. Management of protease inhibitor-associated diarrhea. Clin Infect Dis. 2000;30:908-914.

67. Imodium A-D, and Imodium multi-symptom relief (loperamide and loperamide-simethicone) [package insert]. Fort Washington, PA: McNeil Consumer Healthcare; 2005.

68. Cottreau J, Tucker A, Crutchley R, Garey KW. Crofelemer for the treatment of secretory diarrhea. Expert Rev Gastroenterol Hepatol. 2012;6:17-23.

69. Matheson AJ, Noble S. Racecadotril. Drugs. 2000;59:829-835.

70. MacArthur RD, Hawkins TN, Brown SJ, et al. Efficacy and safety of crofelemer for noninfectious diarrhea in HIV-seropositive individuals (ADVENT trial): a randomized, double-blind, placebocontrolled, two-stage study. HIV Clin Trials. 2013;14:261-273.

71. Golden P, Mathis A, Chu H, et al. Population pharmacokinetic (PK) analysis demonstrates no drug-drug interactions (DDI) between crofelemer, a novel treatment for noninfectious diarrhea in HIV+ individuals, and antiretroviral therapy (ART). Presented at: 53rd Interscience Conference on Antimircobial Agents and Chemotherapy; September 10-13, 2013; Denver, CO.

72. Ilboudo D, Kadio A, Monny L, Mpele P, Ndri-Yoman T, Vohito MD. Therapeutic effect of activated attapulgite mormoiron in related diarrhea syndrome of acquired immunodeficiency (AIDS) [in French]. Medecine d'Afrique Noire. 1997;44:307-312.

73. Razzeca K, Odenheimer S, Davis M, Landeck J, Camino Medical Group. The treatment (TX) of nelfinavir (NFV) induced diarrhea (NFVID) [abstract]. In: Presented at: June 28-July 3, 1998; XII International AIDS Conference, 1998; XII International AIDS Conference, 1998.

74. Chen F, O'Dorisio MS, Hermann G, Hayes J, Malarkey WB, O'Dorisio TM. Mechanisms of action of long-acting analogs of somatostatin. Regul Pept. 1993;44:285-295.

75. Garcia Compean D, Ramos Jimenez J, Guzman de la Garza F, et al. Octreotide therapy of large-volume refractory AIDS-associated diarrhea: a randomized controlled trial. AIDS. 1994;8:1563-1567.

76. Simon DM, Cello JP, Valenzuela J, et al. Multicenter trial of octreotide in patients with refractory acquired immunodeficiency syndrome-associated diarrhea. Gastroenterology. 1995;108: $1753-1760$.

77. Tradtrantip L, Namkung W, Verkman AS. Crofelemer, an antisecretory antidiarrheal proanthocyanidin oligomer extracted from Croton lechleri, targets two distinct intestinal chloride channels. Mol Pharmacol. 2010;77:69-78.

78. Frampton JE. Crofelemer: a review of its use in the management of non-infectious diarrhoea in adult patients with HIV/AIDS on antiretroviral therapy. Drugs. 2013;73:1121-1129. 